\title{
The Study on Social Interaction and Residential Differentiation in Gated Community under the Context of Globalization
}

\author{
Yuefang $\mathrm{Wu}$ \\ Department of Finance and Management \\ Foshan Polytechnic \\ Foshan, China 528137
}

\begin{abstract}
China's private gated community is a kind of material materialization of social public resource supply transforming from unit welfare system to market. Urban gated community is the means to separate residential space, which influences neighborhood structure, residential social interaction and identity perception, forming residential differentiation inside and outside the enclosure in social space. Based on social investigation into Shunde, Guangdong, this paper takes Country Garden Holdings in Shunde and a rural community surround it-Sangui Village as its research objects, discusses social influence of Country Garden Holdings gazed community in Shunde on local communities in the early $1990 \mathrm{~s}$, and analyzes social interaction and interaction mode of social groups which are close to each other geologically with different social and economic status. The research points out that under the special social and cultural background of China, gated community has internal heterogeneity and enclosure as a kind of social "filter net" can't directly guide the homogeneity process of residential space. Various population changes in China's urbanization process continuously influence interaction and identity perception among residents inside and outside the community.
\end{abstract}

Keywords-gated community; identity perception; social interaction; residential differentiation; urban governance

\section{INTRODUCTION}

Gated community with doors and walls and privatization of public space is a pattern of manifestation of post-modern urbanization. It is the result of urban social and economic development, influencing urban society, economy, politics, and culture and so on. Gazed community has various kinds of definition, among which the universally accepted one is "Gated Community" proposed by Blakely and Snyder, American scholars, in 1997, namely "It is a residential area with privatized public space. It restricts access with walls or fences as the boundary generally, adopts remote controlled gates or hires people to watch the gate and guard against outsiders. It can be in the newly developed district or in the re-transformed area. It exists both in the city and in the

Funding: From Assessment to Optimization: research on the third party participation in teaching quality evaluation in advanced vocational education (GDJG2015010). Granted by the Department of Education of Guangdong Province. suburb. It can consist of rich neighborhoods or can be the poor residential area". Although gated community boasts the common feature of homogenesis inside the boundary and heterogeneity outside the community globally, there are evident differences in local features and social significance.

Enclosure (city wall) and fence are the important symbol separating Chinese private and public spaces since ancient times. In planned economy period, as an important source of urban residence supply, a unit is a "courtyard" encircled by enclosures and becomes an internalized space unit for work, life and social function. In house market-oriented-reform period, with continuous development of globalization and urbanization, private gated community starts to appear gradually in urban area. Gated community in modern times is the result of unit welfare system's transformation into marketization and privatization, and it is also regarded as the symbol of beautiful urban life by rich people and the middle class (Pow \& Kong, 2007). As a local response to liberalization of country and regional management under the global transregional language environment, gated community develops from the traditional "management" to the new "governance" mode in terms of urban management thoughts, effectively relieving public department's failure and having important influence on sustainable development of urban public and social space. The research focuses on discussion on social interaction and interaction mode of different social groups that are close to each other geologically but belong to different classes, including community residence's self perception, correlative dependence relation between and social communicative action of communities, and interpreting metaphorical social significance in "enclosure" appearing under the background of global gated community governance.

\section{GATED COMMUNITY: CHALLENGES IN URBAN MANAGEMENT}

Foreign gated community research covers rich themes, including forming mechanism of gated community(Blakely \& Snyder, 1997), the importance of gated community to future urban politics(McKenzie, 1994), efficiency of basic service supply (Foldvary, 1994; Lang \& Danielsen, 1997), gated community residence's satisfaction degree (Carvalho 
et al., 1994; Blakely \& Snyder, 1995; Low, 1995; Castell, 1997), influence of urban material space and social space (Coy \& Pohler, 2002; Grant et al., 2004; Blinnikov et al., 2006 Sullivan, 2003), and gated community's internal and external governance(Barton \& Silverman, 1987; Alexander, 1991; Blakely \& Snyder, 1995; Castell, 1997; Blandy \& Parsons, 2002). Due to its potential effect of social segregation, unfair treatment and social separation, gated community is blamed (Low, 2003). At the same time, urban planning scholars question the isolated plot pattern of selfsupply with enclosures (Marcuse, 1997). These critical views mainly come from LA School's urban researchers or poststructuralists under its influence (Davis, 1990; Conell, 1999; Caldeira, 2000). They put forward the viewpoint established by Michelle Foucault afresh $(1977 ; 1980)$, thinking that "Changes in spatial allocation and space use symbolize the spreading process of power" and they are used in new urban environment of the post-industrialism period. As a new realization model of spatial power, generation and expansion of gated community are regarded as the result of crime, immigration and social unfairness to a large extent (Low, 2001). In addition, urban geographers pay more attention to social space influence of gated community. Development of gated community forms new urban spatial features: The visible "rich island" among the poor ocean in inner city and suburb, namely internal gated community, operates according to privately-owned and anti-foreign principle, thus greatly deviating from public approachability as an important constituent of urban social life quality and intensifying the degree of fragmentation between urban society and urban space. Facing the constantly increasing urban space differentiation phenomena, the urban government seldom puts forward corresponding new governance models, thus making the so-called "no gate area" and "no entry area" great challenges of urban policy and urban planning.

In terms of spatial variation and which kind of isolation is more harmful, there are two choices: The first is creating a long distance between the poor and residence in suburb; the second is using enclosures to reduce the spatial close degree. Chicago school chooses the latter (Webster et al.2002). Through San Diego's research, Sabatini (2001) finds that the existence of gated community is a positive phenomenon even though there is isolation by enclosure, contrary to their viewpoint. Because gated community reduces urban isolation level and becomes the "half-open boundary" among different social groups.

China's gated community experiences the similar process of social decentralization of the US, which expands from the rich's expensive residence to the middle class and even the marginal population (Blakely \& Snyder, 1997). However, different from the US, not all of China's gated communities are in the remote suburb with little population. They can appear in the city and are isolated by enclosures or streets. Due to staged progress of urban renewal and some other reasons, most gated communities are adjacent to private houses in villages in the city. Gated community re-construct citizens' mode of life and neighborly relations and it forms constant and superficial interactive contact with surrounding disordered communities lagging behind relatively, developing a special perception of self-identity and social relation. In Chinese social culture, difference in land and house price leads to difference in individual obtainment of private residential space and accessibility, showing different social groups' differentiation in identity, status, stratum and so on. Spatial difference of housing is also the representation of social difference in geographical location. This paper takes Country Garden Holdings' large gated residential communities in Shunde, Guangdong and Sangui Village which is closely adjacent to it as research objects, and discusses interactive relation between gated community and surrounding villages, perception of resident difference, behavior pattern, and new enlightenment of changes in new urban community organization pattern on urban governance.

\section{CASE LOCATION CONDITION}

Shunde Country Garden Holdings is located in Beijiao Town, Shunde District, Foshan City, Guangdong Province, which borders on Guangzhou and Foshan. Residential land covers Panyu in Guangzhou and Beijiao in Shunde and it is a large life community connecting metropolitan area of Guangzhou and Foshan. Shunde Country Garden Holdings takes the lead in constructing the "Country Garden Holdings homeland model" and innovatively introduces gated community model in terms of property organization and management. It is an innovative community architecture model in South China's real estate market and arouses a construction wave of high-end gated community. Shunde Country Garden Holdings and Sangui Village provide a typical case to research the social influence of gated community.

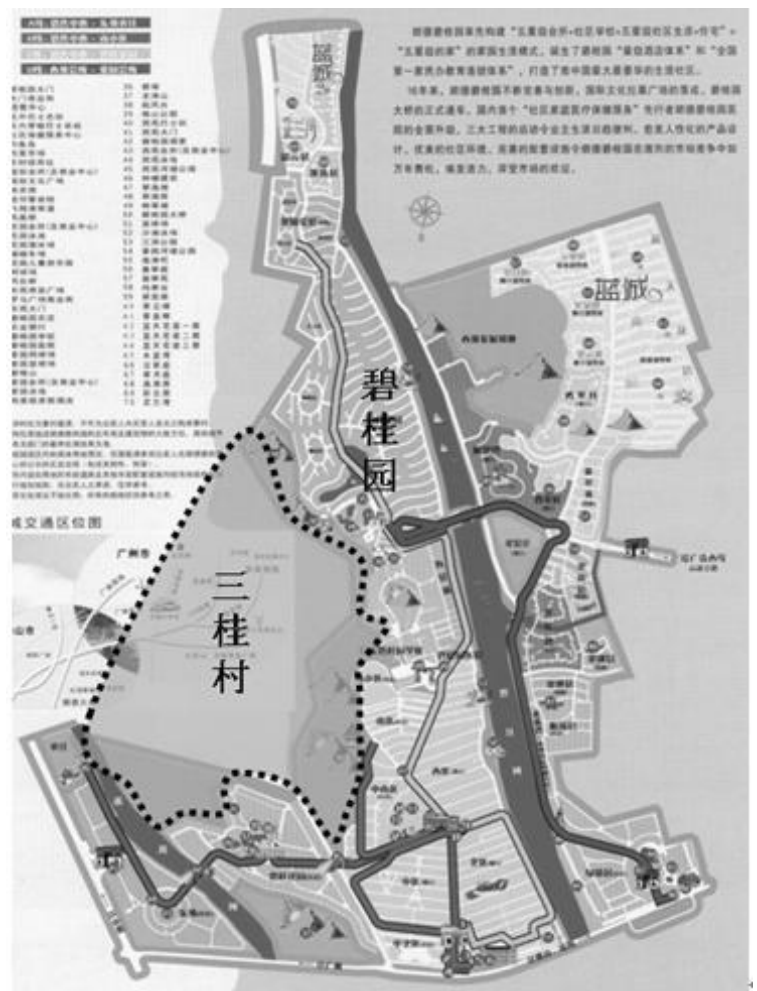

Fig. 1. Relative location of Sangui Village and Country Garden Holdings community. 


\section{RESEARCH METHOD}

The research adopts the qualitative research method. Indepth interviews are conducted on residents living in Shunde Country Garden Holdings and Sangui Village. Selection of interviewees is done randomly and the interview is done in residents' centralized rest area, like riverside, small square, ball park, marketplace and other consumption places. Samples' population distribution features are also considered, like gender, age, job, owner/tenant and so on, in order to make the sample as representative as possible and to reflect key features of this area. The interview is conducted between November of 2012 and November of 2013 and 43 interviewees (20 residents of Country Garden Holdings and 23 residents of Sangui Village) are selected. The time of each interview ranges from 45 minutes to 2 hours.

The interview adopts structuralized questioning framework and main questions include: First, perception of gated community development; second, production, trade and consumption of living resources and services; third, residential and community life experience; fourth, social interaction, communication and construction of social network; fifth, identity perception; sixth, personal essential information etc. At the same time, interviewees can comment about and discuss questions outside the framework freely. Content analysis method is used in material analysis, case oriented strategy is used in sequence analysis and key themes put forward by interviewees are encoded. We analyze every single case, introduce a series of categories and form the main field and thematic structure (Chen Xiangming, 2004).

\section{SHUNDE COUNTRY GARDEN HOLDINGS: IDENTITY} PERCEPTION, LIVING EXPERIENCE AND SOCIAL INTERACTION

\section{A. Residents' Social and Cultural Identity Perception}

In the outside world's eyes, gated communities are alike, where live the stratum with evident homogeneity. However, due to difference in building completion time, house type and location of Shunde Country Garden Holdings community, there is great difference in house price. New and old residents form the residential community of heterogenization, showing evident social and cultural differentiation. In the process of interview, we find that the internal community gathers local ordinary wage-earning class, enterprise senior managers, businessmen, the second residence owner of Hong Kong and so on.

Some conflicts formed due to residents' differentiation are revealed in the interview process. Some residents think that the "upper-class people" living in the community look down upon them. Residents from other provinces especially feel in this way because of the difference in language and living habits.

"There is great difference in household consumption level of Country Garden Holdings. There are people from wage-earning class and rich people. I have no interest in developing more friends in the community, because they are Cantonese and I am from Chongqing. We have different living habits".(Mr. A, a middle school teacher)
With housing system developing from distribution system to market system, urban community population composition develops from regional population aggregation or unit organized gathering to the same income social stratum gathering. In emerging communities, most residents lack the base to know each other, thus creating a cold neighborly relation. According to analysis on human relation type, when karmic connection and geographical relationship are no longer the main constitution form of social population, establishment of residents' contact system can be realized through associative relation and lucky chance relation, which is exactly the thing going on in Country Garden Holdings. Although there are identity perception conflicts between owners and the gated community is not a completely fair, coherent and enclosuring community, a common connection exists inside the community, which forms a contrast between the community and its surrounding villages or villages in the city. Although many interviewees admit that they keep in touch with friends before moving here, they start developing a new circle of friends in the community and start getting adapted to the life here. Children are the most important bond to form a community relation and many residents know each other because of children's joint activities. Besides, middle-aged and old people become the main body crowd of neighborhood communication, which is quite common in China's modern communities.

However, due to little interaction between residents, lack of collective activity in the community, residents' little attention to collective affairs of the community and few situations requiring residents inside the community to decide collectively, the interviewer doesn't believe that community culture with a great filed domain and cohesive force can be formed in the community. Residents have a weak sense of belonging in the community. They think that the perception of home is just limited to their own family and will not expand to the whole community.

"I feel quite good inside the community, but my "home" only refers to my family rather than the whole community of Country Garden Holdings".(Mrs. C, housewife)

\section{B. Perception of Neighboring Villages}

Residents inside the Country Garden Holdings have a positive conception of the surrounding Sangui Village and Bijiang Village. They don't think that there is great difference between external villagers and residents inside the gated community and they are willing to establish a good relationship with them. Some interviewees say that if conditions permitting, they would like to make friends with surrounding villagers.

There are various kinds of motivations to establish the relation. Some residents, especially the elder from Hong Kong, think that nearby villagers have a low living standard and hope to help them through performing benefaction.

The enclosure surrounding Country Garden Holdings directly separates it from nearby villages, bringing the "sense of safety" to internal residents essentially or psychologically and making contact inside and outside the community difficult at the same time. However, different from many 
European or American researchers' viewpoint, the existence of enclosure fails to bring a subjective perception of identity or social status differentiation to residents in Country Garden Holdings. As a half-public product, it satisfies people's need of privatized urban space for special interest or self management. Its appearance in the poor area also enhances the value of local land, making for enhancement of neighboring community's life standard.

\section{SANGUI VILLAGE: COMMUNITY INTERACTION AND RELATIVE ISOLATION}

\section{A. Community Interaction}

Country Garden Holdings' investment in Sangui Village of Beijiao exerts great influence on local material environment and economic development. In the planning and preparation phase, the government speeds up infrastructure investment and supporting facility construction in Sangui Village of Beijiao. The investment is used to complete the "seven accesses and site leveling" in the area, build roads and connect bridges. At the same time, the government assists Country Garden Holdings in completing the levy of land which is required by the construction and dividing shared revenue of the money paid for construction land, thus villagers enjoy the positive external effect brought by Country Garden Holdings and improve their economic status to some extent. After completion of Country Garden Holdings, its influence on Sangui Village's economy and community environment is more prominent, mainly manifesting in consumption increase, community environment improvement and changing local people's life and consumption view through demonstration effect.

Apart from boosting economic development of the community, supporting supermarkets and clubs inside the Country Garden Holdings provide consumption and entertainment places for villagers of Sangui Village. Consumption of villagers of Sangui Village inside Country Garden Holdings is mainly about daily supplies and there is little service product consumption. High-priced consumption and entrance guard limitation make a part of villagers of Sangui Village form a conception of consumption level and social status differentiation. On the one hand, they have expectations for the new, fashionable and high quality environment inside the community of Country Garden Holdings. On the other hand, they worry about differentiation in consumption, clothes and taste arousing conflicts or "discrimination".

We workers seldom enter Country Garden Holdings, because we don't have the card, the things there are expensive. Sometimes, we dare not to enter, because we feel it is too high-ranking and we are embarrassed to go there.(Miss L, an outcomer and grogshop servant, 21 years old)

Due to work relation, residents of Sangui Village enter Country Garden Holdings, but this kind of karmic connection doesn't last long and it is unstable. At the beginning of its establishment, Country Garden Holdings attracts some nearby villagers to work here and some villagers (especially females) begin to do housekeeping, cleaning, maintenance and repair work. However, in recent years, Country Garden Holdings hires more people from other places, reducing its influence on Sangui Village's economy, which reflects the weak economic dependence of Sangui Village on Country Garden Holdings from the side.

Three years ago, I still worked in Country Garden Holdings, helping cook dishes in a school. Having worked there for 11 years, my husband said that I had worked there for such a long time and it was time to quit and look after our own family. Then I resigned. (Mrs H, housewife, more than 40 years old)

\section{B. Enclosure and Segregation of Residential Area}

Sangui Village generally holds a positive attitude towards enclosure's function to the community of Country Garden Holdings itself, thinking enclosure can enhancing Country Garden Holdings' safety and comfort.

Enclosure is to protect people over there and it should exist. If anyone can enter, it will be chaos. I don't feel enclosure brings inconvenience to our life. Enclosure is built where it should be for its own convenience.(Mr. J, retired, more than 70 years old)

For residents of Sangui Village who have checked in and gotten the key card, they feel that enclosure will bring inconvenience to their life and work. However, for residents of Sangui Village who have no key cards, they mostly look upon enclosure from the perspective of an outsider. Some villagers don't care about enclosure at all while some villagers pay some attention to it, but they have no strong rejection feelings and they don't feel that enclosure brings isolation to people's mutual association.

However, to some degree, enclosure enlarges social distance of different contacts inside and outside the community, increases the difficulty for people to communicate, intensifies residents' subjective perception of spatial differentiation and social status differentiation, and adds psychological barriers to residents inside and outside the enclosure. Gated community sets a strict access system. Monitoring system, guard and door card system make it impossible for people who are not residents inside the community to enter. Villagers can't share the public space and riverside landscape which belong to them originally and they form a kind of mental shock, generating a sense of alienation towards residents living inside. This sense is more prominent to the crowds who have no acquaintance in Country Garden Holdings and can't enter Country Garden Holdings.

\section{CONCLUSION}

Insiders of Country Garden Holdings community and Sangui Village have a weak common conception of community identity and a weak sense of belonging. Community identity is not formed conformingly among residents. Post-structuralist and LA School think that the existence of enclosure intensifies social bond inside the gated community and has negative emotion and response towards 
peripheral communities. Based on research, Sennett (1977) thinks that separated community makes it difficult to sustain people's social relation and makes them hostile groups unworthy to know about. However, seeing from interviews in the research, LA School's passive analytical conclusion obtains no certification from the relation between Country Garden Holdings and Sangui Village and is predicated impossible to appear in other gated communities of China.

In terms of psychological feeling and social contact, gated community doesn't make residents outside the enclosure feel envious, frustrated or unhappy. On the contrary, villagers of Sangui Village think that gated community brings modernization to the local place and improves living environment, which is generally neglected by urban planners. In addition, gated community introduces public transportation, electric power system, security system, better road facilities and employment chances, and enhances local consumption. Material enclosure doesn't exclude the possibility that social relation can be established between two communities. Residents inside the enclosure don't regard villagers of Sangui Village as enemies or people creating uneasy elements, therefore they can relaxingly buy goods from shops in Sangui Village and provide jobs for them

As to material flow and spatial usage, enclosure has partial sheltering effects. Entrance guard's material obstruction makes villagers lacking close relationship or karmic connections with people inside the gated community unable to enter, thus these villagers can do nothing but look into the rich supporting facilities, high quality community landscape and a wide variety of imported goods remotely. Gated community gathers people with similar consumption power and social identity in certain urban space through house price strategy, thus enclosure plays the role of social filter screen.

The research also points out that the gated people inside the community are not totally of the same nature. A large number of migrant populations from other places or rural people coming here to get engaged in industry or project may also live in the gated community. Their mobility makes people inside the enclosure and residents in villages in the city form a natural bond. At the same time, people inside the enclosure haven't formed a solidified stratum and residents inside the gated community have great differences manifested in education, employment, income, occupation and so on. Living in the same community can't bring about the same social recognition, therefore there is a continuous conflict among residents' social identity and residential perception inside the community.

Seeing from China's macro social background, middle class is still a unstable social stratum, which is still weak. China's middle class is close to the upper class in income and education background and close to the lower class in political status and consumption features. The middle class itself has strong class mobility, based on which the class isolation function of enclosure is not prominent. Enclosure of China's gated community mostly shoulders the role of segmentation and protective screen in residential area. It has a limited function in social space isolation and hasn't developed into the extreme "fortress community" class form of gated community in foreign countries.

Gated community is formed under certain social and economic development background and it is the inevitable product of urban citizen's personal choice, market-oriented development and local government and it is a phase of urban management development transformation. Gated community's governance model under the contractual law system plays an important role in improving community environment, providing improved public service, safeguarding residents' personal and property safety and satisfying residents' need of exclusiveness. But many internal and structural problems and conflicts exist. Under the background of China's transformational society and new urban governance model, it is of great significance to formally plan, guide and come up with corresponding policies in terms of construction and development of gated community and to provide norms and instructions for gated community's architectural form, public and private facilities, road connectivity inside and outside the community, environment design and crime prevention.

\section{REFERENCES}

[1] Blakely, E., \& Snyder, M.G. (1997). Fortress America: gated communities in the United States. Washington, D.C., Brookings Institution Press.

[2] Coy, M. (2006) Gated communities and urban fragmentation in Latin America: the Brazilian experience. GeoJournal, 66, pp.121-132.

[3] Fishman, R. (1987) Bourgeois utopias: the rise and fall of suburbia,Basic Books, New York.

[4] Foldvary, F. (1994) Public goods and private communities: the market provision of social services. Edvard Elgar, London.

[5] Grant, J. (2005) Planning responses to gated communities in Canada. Housing Studies, 20(2), pp. 273-284

[6] Grant, J., Katherine, G., \& Kirstina, M. (2004) The planning and policy implication of gated communities. Canadian Journal of Urban Research, 13(1), pp.70-88.

[7] Lang, R. \& K. Danielsen (1997) Gated communities in America:walling out the world? Housing Policy Debate 8(4), pp.7257.

[8] Low, S. (2001) The edge and the center: gated communities and the discourse of urban fear. American Anthropologiet. 103(1), pp.45-58

[9] Low, S. (2003) Behind the Gates: Life, Securityand the Pursuit of Happiness in Fortress America. Routledge, New York.

[10] Marcuse, P. (1997) The ghetto of exclusion and the fortified enclave American Behavioral Scientist 41(3), pp.311-336

[11] Pow, C.P., \& Kong, L. Marketing the Chinese dream home: gated communities and representations of the good life in (Post-) socialist Shanghai. Urban Geography, 2007, 28(2): 129-159.

[12] Sabatini, F., G. Caceres \& A. Cerda (2001) Segregacion residential en las pricipales ciudades chilenas: tendencias de las tres ultimas decadas y posibles cursos de accion. Eure XXVII. 82, pp.21-42

[13] Webster, C.(2001) Gated cities of tomorrow. Town Planning Review $72.2,149-69$

[14] Webster, C., G. Gasze and K. Frantz. (2002) The global spread of gated communities. (Guest editorial), Environment and Planning B 29(3), pp.315-20.

[15] Wu, Fulong. (2005) Rediscovering the 'gate' under market transition from work-unit compounds to commodity housing enclaves. Housing Studies,20(2), pp.235-255.

[16] Chen Jifang(1986). Social Psychology. Zhengzhou: Henan People's Press, 353-354. 
[17] Chen Xiangming. How to Become a Qualitative Research. Education and Science Publishing House, 2004.

[18] Qin Ruiying, Yan Xiaopei, Cao Xiaoshu. Foreign Urban Gated Community and Governance. Economic Geography. 3(28), 401-406.

[19] Song Weixuan. Gated Community Research Progress. City Planning Forum, 2010, 4,42-51. 